\title{
SUFFICIENT CONDITIONS FOR CONVEXITY IN A CLASS OF FUNCTIONS ARISING IN TELECOMMUNICATIONS
}

\author{
M. Peake And C. E. M. PeArCe
}

Abstract. Convexity is a key property for a class of functions arising in telecommunications. We derive sufficient conditions for this to hold.

Mathematics subject classification (2000): 60K25, 26D15.

Key words and phrases: $G I / M / N / N$ loss system, time congestion, convexity.

\section{REFERENCES}

[1] A. J. CoYLe, Sensitivity bounds in a $G I / M / n / n$ system, J. Austral. Math. Soc. Ser. B, 31, (1989), $135-149$.

[2] A. E. ECKBERG, Sharp bounds on Laplace-Stieltjes transforms with applications to various queueing problems, Math. Oper. Res. 2, (1977), 135-142.

[3] M. PEAKE, C. E. M. PEARCE, On an extremal problem arising in queueing theory and telecommunications, Optimization \& Related Fields, Eds A. Rubinov \& B. Glover, Kluwer, Dordrecht (2001), 119-134.

[4] M. PEAKE, C. E. M. PEARCE, On a convexity problem arising in queueing theory and electromagnetism, Differential Equations \& Applications, Vol. 2, Eds Y. J. Cho, J. K. Kim \& K. S. Ha, Nova, Huntingdon (2002), 149-158.

[5] C. E. M. PEARCE, Quasiconvexity, fractional programming and extremal traffic congestion, Frontiers in Global Optimization, Eds C. A. Floudas and P. M. Pardalos, Nonconvex Optimization and its Applications, 74, (2004), 403-409.

[6] L. TAKÁCs, Introduction to the Theory of Queues, Oxford University Press, New York 1962. 